\title{
An Analysis of the Differences in Overseas Buyers' Perception on Korean Consumer Products
}

\author{
Hye-Joo Song ${ }^{1}$, Jung-Wan Hong ${ }^{2} \&$ Yen-yoo You ${ }^{2}$ \\ ${ }^{1}$ Dept. of Knowledge Service \& Consulting, Hansung University, Seoul, South Korea \\ ${ }^{2}$ Division of Smart Management Engineering, Hansung University, Seoul, South Korea \\ Correspondence: Jung-Wan Hong, Professor, Division of Smart Management Engineering, Hansung University, \\ Seoul, South Korea. Tel: 82-10-7587-4329. E-mail: jwhong@ hansung.ac.kr
}

Received: April 9, 2020

Accepted: May 9, 2020

Online Published: May 23, 2020

doi:10.5430/rwe.v11n2p90

URL: https://doi.org/10.5430/rwe.v11n2p90

\begin{abstract}
Background/Objectives: This study is about the difference of perception among overseas buyers who are interested in Korean consumer goods. The purpose of this study is to analyze whether there is a difference in price, quality, differentiation (uniqueness), reliability, and post-consultation intention for buyers to purchase representative consumer products in Korea.

Methods/Statistical analysis: For the research method, we surveyed 420 overseas buyers who participated in the SME Consumer Goods Product Purchasing Meeting held in Seoul in 2019. 660 valid surveys were collected from infant, cosmetic, fashion, food and household buyers in Southeast Asia, China, Japan and other regions (Europe, USA, CIS). With SPSS22.0, we analyzed exploratory factors and reliability of Korean buyers' characteristics and overseas buyers' evaluation criteria for Korean companies and products. And, ANOVA was used to examine the difference in buyers' awareness of consumer goods and product characteristic.

Findings: According to the analysis results, there is a difference in recognition of price and trading intentions for the product group (baby goods, cosmetics, fashion goods, food and household goods, etc.) regardless of the buyer's region. Therefore, price correlates with buying decisions and it can be seen that price influences trading decisions. However, there is no difference in perception in quality, differentiation and reliability, and we can see that the quality of consumer products in Korea is generally well received and high in reliability. On the other hand, buyers from different regions showed differences in perception in price, quality, and reliability, but there were no perception differences in product differentiation or intention to trade. Therefore, although prices, quality, and reliability are evaluated differently, it can be seen that there is a high willingness to trade in acknowledgment of product differentiation or uniqueness.

Improvements/Applications: In the future, it is hoped that the research will be conducted only for buyers in Southeast Asian countries, and through this, it will be possible to establish marketing strategies by analyzing buyer tendency of each country in Southeast Asian countries. In addition, we hope to analyze more specific marketing points through research linking buyers' evaluations with the performance of domestic companies.
\end{abstract}

Keywords: SME (small \& medium size enterprises), consumer goods, price, product quality, differentiation, reliability

\section{Introduction}

Although Korea has analyzed a lot of export competitiveness in major countries, few studies have analyzed the Southeast Asian market in a similar way (Yeo, 2019). Comparing the recent five-year annual growth rate of exports to Southeast Asian markets, cosmetics in Indonesia, cosmetics and fashion clothing and pharmaceuticals in Thailand, and cosmetics in Vietnam show high export growth rates (Choi et al., 2018). The Korean government will announce the "Activation Measures for Consumer Goods Export Promotion" and create new economic growth engines by expanding the export of consumer goods by spreading the Korean Wave (Choi et al., 2018). The purpose of this study is to analyze the differences in the perception of buyers around the world on the price, quality, differentiation, reliability, and trading intention of consumer products in Korea. In addition, this study examines the differences in the perceptions of Korean consumer goods by buyers from different regions of the world. Through this study, it is possible not only to confirm how global buyers are evaluating domestic consumer products in the above conditions, but also to create a consumer 
goods export strategy for buyers in each region. It is also hoped that the results of this study can be used to create differentiated consumer goods export strategies for Southeast Asian countries.

\section{Materials and Methods}

\subsection{Theoretical Background}

Perception is the subjective judgment on the actual performance of the goods or services that received or experienced by customer (Wilson et al., 2019).

\subsubsection{Price \& Product Quality}

Since the 1960s, many researchers explain that there is a high correlation between commodity prices and consumers' perceptions of quality, so it is likely that commodity prices and quality will be perceived as proportional (Jeon, 2019). Various previous studies have shown that product quality, product price, product diversity and product image which make up product characteristics factors, have a positive effect on consumer's purchase satisfaction (Park, 2019). And, overall satisfaction is positively associated with attitude loyalty (intention to trade) (Chiou and Droge, 2006). Also, product quality refers to customer perceptions of the excellence in a supplying firm's product offering in terms of meeting customer requirements with attention to technical aspects (Paparoidamis et al., 2019).

\subsubsection{Reliability \& Differentiation}

The role of trust in developing relationships seems to be a key variable in creating long-lasting bonds in French business culture (Newell et al., 2017). Similarly, most of the variables did not have any significant relationship with the demographics studied, except between trust and experience and this correlation is in line with $\mathrm{H} 2$ that 'customer satisfaction is positively related to trust of customers' (Sulphey and George, 2017). Trust is thought to provide trading partners with a competitive advantage, because it facilitates investments in relationship assets, encourages information sharing, and generally lowers transaction costs (Katsikeas et al., 2009), and our survey results from importers trading with overseas manufacturers suggest that existing levels of trust have a positive effect on relationship performance outcomes achieved 1 year later (Katsikeas et al., 2009). Consequently, we expected buyer perceptions of supplier and salesperson expertise and trust to be higher when the purchase was perceived as extremely important than for those purchases that were perceived as minimally important (Belonax et al., 2007).

\subsubsection{Purchasing Power}

Customer characteristics refer to differences between the home and export markets in the level of customer sensitivity to sustainability-linked marketing strategy aspects, such as product evaluation criteria, product usage patterns, and purchasing criteria (Zeriti et al., 2014). And, they have more opportunities to reveal their social preferences when engaging in purchasing should they choose to do so (Auger et al., 2010).

\subsection{Research Model}

The purpose of this study is to analyze whether there is a difference in perceptions on product and by regional buyers regarding the factors that foreign buyers interested in Korea's consumer products have in making trade decisions. The product range was limited to baby products, cosmetics, fashion goods, food and household goods, which were selected by the Korean government as five representative consumer goods. The factors to be considered are extracting price, quality, differentiation, reliability and intention of transaction through preceding studies, and presenting a research model as shown in [Figure 1] to confirm the difference in recognition of the factors.

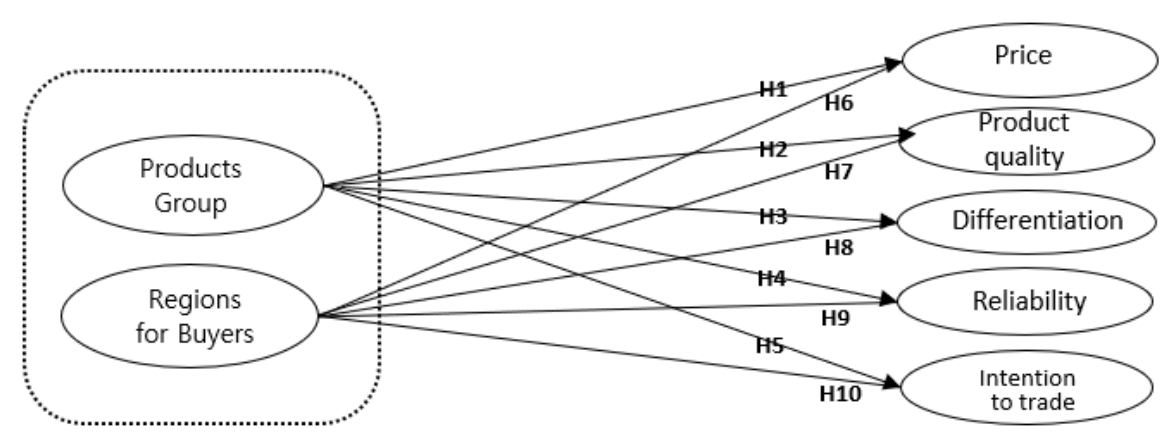

Figure 1. Research model 


\subsection{Research Hypothesis}

The following hypotheses were established through previous studies to identify the difference in perception of the influence of each factor considered in the trade decision of overseas buyers.

H1 There will be a difference in the perception of the price of the products depending on the consumer goods group in Korea.

H2 There will be a difference in the perception of the quality of the products depending on the consumer goods group in Korea.

There will be a difference in the perception of the differentiation of the products depending on the consumer goods group in Korea.

There will be a difference in the perception of the reliability of the products depending on the consumer goods group in Korea.

There will be a difference in the perception of trading intentions of the products depending on the consumer goods group in Korea.

H6 The perception of prices for Korean consumer goods will vary by buyer's region.

H7 The perception of the quality of Korean consumer goods will vary by buyer's region.

H8 The perception of the differentiation of Korean consumer goods will vary by buyer's region.

H9 The perception of the reliability of Korean consumer goods will vary by buyer's region.

H10 The perception of trading intentions with Korean consumer goods will vary by buyer's region.

\subsection{Research Methods}

\subsubsection{Sample Selection}

The sample for this study was taken from 420 overseas buyers and Korean consumer goods companies who participated in the Korea SME Consumer Goods Product Meeting held in Seoul in 2019. Buyers dealing with baby products, cosmetics, fashion products, food and household goods visited Korea to discuss the purchase of Korean consumer goods. We analyzed 668 valid surveys collected from buyers who had a meeting for contract with domestic companies.

\subsubsection{Operational Definition and Measurement of Variables}

The measure of dependent variables is divided into factors that buyers consider in trading and factors that Korean companies evaluate buyers. These metrics were extracted from previous studies, and some o them were modified and supplemented with those commonly used in the researcher's work (Moses, 2017); (Mousa, 2019). The survey was conducted on both the consideration factors of buyers and the evaluation factors of Korean companies, but, in this study, the differences were analyzed only for the factors that buyers consider in trading. Through the preceding studies, the factors considered in the transaction were extracted price, quality, differentiation, reliability, and trading intention.

\subsubsection{Statistical Analysis Method}

668 valid responses from buyers were analyzed by SPSS22.0, exploratory factor analysis and reliability analysis. As a result, KMO was found to be .879 , and Cronbach's $\alpha=.952$ was measured by Korean companies, and Cronbach's $\alpha$ $=.908$ was measured by Korean companies. The result is shown in [Table 2] below. On the other hand, the results of testing the difference through ANOVA to find the difference in recognition of the factors that buyers consider in order to to business with Korean companies are as follows [3.3.1. 3,3,5,].

\section{Results and Discussion}

\subsection{Sample Characteristics}

To find the general characteristics of the sample used in this study, frequency analysis was conducted, and the characteristics of sample are shown in [Table 1] below. 
Table 1. Sample characteristics

$(\mathrm{N}=668)$

\begin{tabular}{ccc}
\hline Variables & Characteristic & $\mathbf{N}(\%)$ \\
\hline & Baby goods & $120(18.0)$ \\
Products & Cosmetics & $133(19.9)$ \\
& Fashion goods & $125(18.7)$ \\
& Foods & $146(21.9)$ \\
& Household goods & $144(21.6)$ \\
\hline \multirow{2}{*}{ Regions } & Southeast Asia Countries & $179(26.8)$ \\
& China & $170(25.4)$ \\
& Japan & $164(24.6)$ \\
\hline
\end{tabular}

\subsection{Validity and Reliability Analysis}

For validity testing of variables to be used in this study, exploratory factor analysis and reliability analysis were conducted, the results are shown in [Table 2] below.

Table 2. Exploratory factor analysis and reliability (Exogenous variables)

\begin{tabular}{lccc}
\hline \multicolumn{1}{c}{ Measurement variables } & $\begin{array}{c}\text { Buyer } \\
\text { Characteristics }\end{array}$ & $\begin{array}{c}\text { Korean Product and } \\
\text { Company Characteristics }\end{array}$ & Cronbach's $\boldsymbol{\alpha}$ \\
\hline Trust & $\mathbf{. 9 4 8}$ & .039 & \\
Professionalism & $\mathbf{. 9 3 4}$ & .056 & .952 \\
Purchasing Power & $\mathbf{. 2 8}$ & .005 & \\
Concentration to meeting & $\mathbf{. 8 9 6}$ & .107 & \\
Trading Possibility & $\mathbf{. 8 7 4}$ & .090 & .908 \\
\hline Reliability & .040 & $\mathbf{. 8 9 8}$ & \\
Product Quality & .060 & $\mathbf{. 8 8 5}$ & \\
Differentiation & .023 & $\mathbf{. 8 8 0}$ & \\
Intention to Trade & .073 & $\mathbf{. 8 2 6}$ & \\
Price & .080 & $\mathbf{. 7 9 6}$ & \\
\hline \multicolumn{1}{c}{$\mathrm{EV}$} & 4.218 & 3.705 & \\
\multicolumn{1}{c}{$\mathrm{V}(\%)$} & 42.184 & 37.048 \\
\multicolumn{1}{c}{$\mathrm{AV}(\%)$} & 42.184 & 79.232 \\
\hline
\end{tabular}

$\mathrm{KMO}=.879$, Bartlett $\mathrm{x}^{2}=6,016.420, \mathrm{p}=.000$

\subsection{Research Model Analysis}

The purpose of this study is to examine the differences in perceptions of buyers' purchases of representative consumer goods(baby goods, cosmetics, fashion goods, foods and household goods, etc.) in Korea, in terms of price, quality, differentiation, reliability, and influence on post-trading intention by product group and buyer region. ANOVA was performed, and the results are as shown below [3.3.1 3.3.5.].

\subsubsection{Analysis on the Difference in Price Perception by Product Group and Buyer's Region}

ANOVA was conducted to find out the difference in the perception of prices according to the products group and the region of buyers that consulted with Korean consumer goods companies. As shown in [Table 3], there were differences depending on the product group $(\mathrm{p}<.05)$ and the buyer's region $(\mathrm{p}<.05)$. 
Table 3. Analysis on the difference in perceptions of price

\begin{tabular}{|c|c|c|c|c|c|}
\hline & & M & SD & $\mathrm{t} / \mathrm{F}$ & $\mathrm{p}$ \\
\hline \multirow{5}{*}{ Products } & Baby goods & 3.48 & 1.00 & 5.87 & $.000 * * *$ \\
\hline & Cosmetics & 3.71 & .96 & & \\
\hline & Fashion goods & 3.30 & 1.03 & & \\
\hline & Foods & 3.79 & 1.13 & & \\
\hline & Household goods & 3.35 & 1.05 & & \\
\hline \multirow{4}{*}{ Regions } & Southeast Asia Countries & 3.40 & 1.08 & 2.97 & $.031 *$ \\
\hline & China & 3.52 & 1.09 & & \\
\hline & Japan & 3.51 & .99 & & \\
\hline & Other(North America, Europe, CIS) & 3.74 & 1.01 & & \\
\hline
\end{tabular}

3.3.2 Analysis on the Difference in Product Quality Perception by Product Group and Buyer's Region

ANOVA was conducted to find out the difference in the perception of product quality according to the products group and the region of buyers that consulted with Korean consumer goods companies. As shown in [Table 4], there was no recognition difference for the product group $(\mathrm{p}=.451>.05)$, but there was d difference according to the buyer's $\operatorname{region}(\mathrm{p}<.05)$.

Table 4. Analysis on the difference in perceptions of product quality

\begin{tabular}{|c|c|c|c|c|c|}
\hline & & $\mathrm{M}$ & SD & $\mathrm{t} / \mathrm{F}$ & $\mathrm{p}$ \\
\hline \multirow{5}{*}{ Products } & Baby goods & 3.89 & .92 & 0.92 & .451 \\
\hline & Cosmetics & 4.05 & .92 & & \\
\hline & Fashion goods & 3.00 & 1.00 & & \\
\hline & Foods & 4.10 & .96 & & \\
\hline & Household goods & 4.00 & .89 & & \\
\hline \multirow{4}{*}{ Regions } & Southeast Asia Countries & 3.91 & 1.04 & 3.92 & $.009 * *$ \\
\hline & China & 4.05 & .96 & & \\
\hline & Japan & 3.90 & .87 & & \\
\hline & Other(North America, Europe, CIS) & 4.21 & .82 & & \\
\hline
\end{tabular}

\subsubsection{Analysis on the Difference in Differentiation Perception by Product Group and Buyer's Region}

ANOVA was conducted to find out the difference in the perception of differentiation according to the products group and the region of buyers that consulted with Korean consumer goods companies. As shown in [Table 5], there was no recognition difference according to product group $(\mathrm{p}=.393>.05)$ and buyers' region $(\mathrm{p}=.098>.05)$.

Table 5. Analysis on the difference in perceptions of differentiation

\begin{tabular}{|c|c|c|c|c|c|}
\hline & & $\mathrm{M}$ & $\mathrm{SD}$ & $\mathrm{t} / \mathrm{F}$ & t \\
\hline \multirow{5}{*}{ Products } & Baby goods & 3.86 & .99 & 1.027 & .393 \\
\hline & Cosmetics & 3.94 & .98 & & \\
\hline & Fashion goods & 3.99 & 1.00 & & \\
\hline & Foods & 4.02 & 1.01 & & \\
\hline & Household goods & 3.82 & .98 & & \\
\hline \multirow{4}{*}{ Regions } & Southeast Asia Countries & 3.87 & 1.06 & 2.110 & .098 \\
\hline & China & 3.96 & 1.01 & & \\
\hline & Japan & 3.81 & .90 & & \\
\hline & Other(North America, Europe, CIS) & 4.07 & .97 & & \\
\hline
\end{tabular}


3.3.4 Analysis on the Difference in Reliability Perception by Product Group and Buyer's Region

ANOVA was conducted to find out the difference in the perception of reliability according to the products group and the region of buyers that consulted with Korean consumer goods companies. As shown in [Table 6], there was no differences in product group ( $\mathrm{p}=.383>.05)$, and there was a difference in recognition in buyers' region $(\mathrm{p}<.05)$.

Table 6. Analysis on the difference in perceptions of reliability

\begin{tabular}{llrrrr}
\hline & & $\mathrm{M}$ & $\mathrm{SD}$ & $\mathrm{t} / \mathrm{F}$ & $\mathrm{p}$ \\
\hline \multirow{5}{*}{ Products } & Baby goods & 3.77 & .94 & 1.046 & .383 \\
\cline { 2 - 6 } & Cosmetics & 3.95 & .96 & & \\
\cline { 2 - 6 } & Fashion goods & 3.83 & 1.00 & & \\
\cline { 2 - 6 } & Foods & 3.97 & 1.04 & & \\
\cline { 2 - 6 } & Household goods & 3.83 & .97 & & \\
\hline \multirow{5}{*}{ Regions } & Southeast Asia Countries & 3.79 & 1.04 & 3.850 & $.01 * *$ \\
\cline { 2 - 6 } & China & 4.02 & 1.00 & & \\
\cline { 2 - 6 } & Japan & 3.71 & .91 & & \\
\cline { 2 - 6 } & Other(North America, Europe, CIS) & 3.97 & .95 & & \\
\hline
\end{tabular}

3.3.5 Analysis on the Difference in Trade Intention Perception by Product Group and Buyer's Region

ANOVA was conducted to find out the difference in the perception of trade intention according to the products group and the region of buyers that consulted with Korean consumer goods companies. As shown in [Table 7], there was a difference in the product group $(\mathrm{p}<.05)$, and there was no difference in recognition in the buyer's region $(\mathrm{p}=.076>.05)$.

Table 7. Analysis on the difference in perceptions of trade intention

\begin{tabular}{llllll}
\hline & & $\mathrm{M}$ & $\mathrm{SD}$ & $\mathrm{t} / \mathrm{F}$ & $\mathrm{p}$ \\
\hline \multirow{5}{*}{ Products } & Baby goods & 3.49 & 1.12 & 4.761 & $.001^{* * *}$ \\
\cline { 2 - 6 } & Cosmetics & 3.79 & 1.00 & & \\
\cline { 2 - 6 } & Fashion goods & 3.29 & 1.31 & & \\
\cline { 2 - 6 } & Foods & 3.73 & 1.21 & & \\
\cline { 2 - 6 } & Household goods & 3.37 & 1.16 & & \\
\hline \multirow{5}{*}{ Regions } & Southeast Asia Countries & 3.44 & 1.19 & 2.306 & .076 \\
\cline { 2 - 6 } & China & 3.64 & 1.18 & & \\
\cline { 2 - 6 } & Japan & 3.41 & 1.17 & & \\
\cline { 2 - 6 } & Other(North America, Europe, CIS) & 3.68 & 1.16 & & \\
\hline
\end{tabular}

\subsection{Results of Hypothesis Testing}

The result of hypothesis testing are shown in [Figure 2] and [Table 8] below.

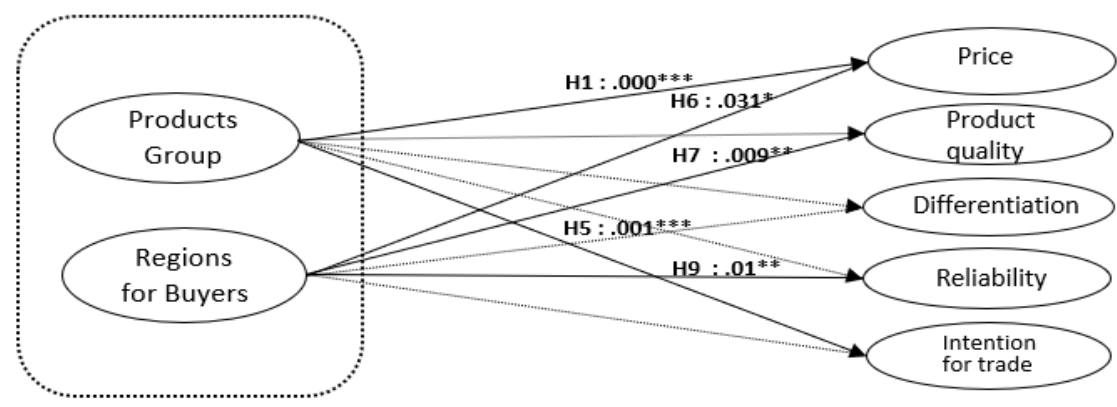

Figure 2. Results of hypothesis test

$* \mathrm{p}<.05, * * \mathrm{p}<.01, * * * \mathrm{p}<001$ 
Table 8 . The results of hypothesis testing

\begin{tabular}{|c|c|c|}
\hline Hypothesis & Hypothesis to be tested & Results \\
\hline $\mathrm{H} 1$ & $\begin{array}{l}\text { There will be a difference in the perception of the price of the products } \\
\text { depending on the consumer goods group in Korea }\end{array}$ & Accept \\
\hline $\mathrm{H} 2$ & $\begin{array}{l}\text { There will be a difference in the perception of the quality of the products } \\
\text { depending on the consumer goods group in Korea. }\end{array}$ & Reject \\
\hline $\mathrm{H} 3$ & $\begin{array}{l}\text { There will be a difference in the perception of the differentiation of the } \\
\text { products depending on the consumer goods group in Korea. }\end{array}$ & Reject \\
\hline $\mathrm{H} 4$ & $\begin{array}{l}\text { There will be a difference in the perception of the reliability of the products } \\
\text { depending on the consumer goods group in Korea. }\end{array}$ & Reject \\
\hline $\mathrm{H} 5$ & $\begin{array}{l}\text { There will be a difference in the perception of trading intentions of the } \\
\text { products depending on the consumer goods group in Korea. }\end{array}$ & Accept \\
\hline H6 & $\begin{array}{l}\text { The perception of prices for Korean consumer goods will vary by buyer's } \\
\text { region. }\end{array}$ & Accept \\
\hline $\mathrm{H} 7$ & $\begin{array}{l}\text { The perception of the quality of Korean consumer goods will vary by buyer's } \\
\text { region. }\end{array}$ & Accept \\
\hline $\mathrm{H} 8$ & $\begin{array}{l}\text { The perception of the differentiation of Korean consumer goods will vary by } \\
\text { buyer's region. }\end{array}$ & Reject \\
\hline $\mathrm{H} 9$ & $\begin{array}{l}\text { The perception of the reliability of Korean consumer goods will vary by } \\
\text { buyer's region. }\end{array}$ & Accept \\
\hline H10 & $\begin{array}{l}\text { The perception of trading intentions with Korean consumer goods will vary } \\
\text { by buyer's region. }\end{array}$ & Reject \\
\hline
\end{tabular}

\section{Conclusion}

\subsection{Result Summary and Implication}

This study was conducted to find out, depends on the product group and the region of the buyers, whether there is a difference in the perceptions of factors that are considered when deciding to trade after overseas buyers had a meeting to purchase Korean consumer goods (Nzeribe, 2019); (Obeng, 2018); (Obim et al., 2018). Research shows that there is a difference in perception on price $(\mathrm{p}<.05)$ and trading intention $(\mathrm{p}<.05)$ and there was no difference in quality $(\mathrm{p}=.451>.05)$, differentiation $(\mathrm{p}=.393>.05)$, and reliability $(\mathrm{p}=.383>.05)$ for products group. On the other hand, depending on buyers' regions, there were differences in price $(p<.05)$, and reliability $(p<.05)$, and differentiation $(\mathrm{p}=.098>.05)$ and differentiation ( $\mathrm{p}=.098>.05)$, purchase intention $(\mathrm{p}=.076>.05)$ showed no difference. In conclusion, while buyers' interest in Korean consumer goods has increased due to the boon in the Korean Wave, there are differences on buyers' perceived prices for products such as baby products, cosmetics, and fashion products. It can be seen that this also affects the final purchase intention. However, there is no difference in perception of quality, differentiation, and reliability, indicating that overall recognition of Korean consumer products is good. Given the differences in perceptions in price quality and reliability among buyers' regions, it is clear that developed countries and developing countries need to differentiate in terms of price and quality. In addition, although there is a difference in the perception of price and quality, the recognition of the difference or the intention of the final transaction shows that Korean products have a good evaluation.

\subsection{Limitation and Future Direction}

Initially, at the start of the study, I would like to do detailed research on consumer goods buyers in Southeast Asia. The plan was changed to prioritize seeing the universal perception of world buyers. In the future, it is necessary to study in detail by region, starting with Southeast Asia.

\section{Acknowledgment}

This research was financially supported by the Hansung University.

\section{References}

Auger, P., Devinney, T. M., Louviere, J. J., \& Burke, P. F. (2010). The importance of social product attributes in consumer purchasing decisions: A multi-country comparative study. International Business Review, 19(2), 
140-59.

Belonax. Jr J. J., Newell, S. J., \& Plank, R. E. (2007). The role of purchase importance on buyer perceptions of the trust and expertise components of supplier and salesperson credibility in business-to-business relationships. Journal of Personal Selling \& Sales Management, 27(3), 247-58.

Chiou, J. S., \& Droge, C. (2006). Service quality, trust, specific asset investment, and expertise: Direct and indirect effects in a satisfaction-loyalty framework. Journal of the Academy of Marketing Science, 34(4), 613-27.

Choi, B. Y., Lee, S. Y., Lee, H. K., Lee, B. R., \& Lee, J. E. (2018). Korea's export activation plan of consumer goods to Southeast Asia. [KIEP] Research Report, 18(25), 1-210.

Jeon, H. S. (2019). Effect of commodity price on quality recognition. -Focusing on the moderating effect of price fairness in distribution channels. Consumer Culture Research, 22(3), 97-119. https://doi.org/10.17053/jcc.2019.22.3.005

Katsikeas, C. S., Skarmeas, D., \& Bello, D. C. (2009). Developing successful trust-based international exchange relationships. Journal of International Business Studies, 40(1), 132-55.

Moses, O. (2017). Modeling optimal debt and expenditure in Malawi: A dynamic optimization approach. Asian Journal of Economic Modelling, 5(4), 402-412.

Mousa, E. Y. (2019). Analytical study of factors affecting investment in Saudi Arabia from the period of $1990-2017$. International Journal of Applied Economics, Finance and Accounting, 4(1), 10-14. https://doi.org/10.33094/8.2017.2019.41.10.14

Newell, S. J., Lapoule, P., \& Leingpibul, D. (2017). Understanding the role of trust and expertise when developing businesses-to-business relationships in France. Journal of Selling, 18(1), 31-46.

Nzeribe, A. (2019). Appointment of directors and performance of deposit money banks in Sub Saharan Africa: Do we need more executive or non-executive directors?. Journal of Empirical Studies, 6(1), 1-18.

Obeng, G. (2018). Value added tax and vat flat rate scheme in Ghana, any cascading implications. Asian Development Policy Review, 6(4), 213-225.

Obim, E. N., John, J. I., \& Orok, A. B. (2018). Interest rate policy and the growth of the Nigerian economy (1990-2016). Journal of Banking and Financial Dynamics, 2, 16-23.

Paparoidamis, N. G., Katsikeas, C. S., \& Chumpitaz, R. (2019). The role of supplier performance in building customer trust and loyalty: A cross-country examination. Industrial Marketing Management, 78, 183-97.

Park, J. H. (2019). An empirical study on satisfaction and repurchase intention of Indonesian consumers purchasing Korean products through online shopping mall. [Dissertation]. [Seoul]: Hannam University, p. 60.

Sulphey, M. M., \& George, S. (2017). A study on the relationship between customer satisfaction, business ethics and certain related variables. Journal of Applied Management and Investments, 6(1), 67-75.

Wilson, N., Keni, K., \& Tan, P. H. (2019). The effect of website design quality and service quality on repurchase intention in the e-commerce industry: A cross-continental analysis. Gadjah Mada International Journal of Business, 21(2), 187.

Yeo, T. D. (2019). A study of Korea's trade strategy toward Vietnam. International Commerce and Information Review, 21(2), 95-121.

Zeriti, A., Robson, M. J., Spyropoulou, S., \& Leonidou, C. N. (2014). Sustainable export marketing strategy fit and performance. Journal of International Marketing, 22(4), 44-66. 